\title{
All-Red-Light Photoswitching of Indirubin Controlled by Supramolecular Interactions
}

\author{
Stefan Thumser, Laura Köttner, Nadine Hoffmann, Peter Mayer, and Henry Dube*
}

Cite This: J. Am. Chem. Soc. 2021, 143, 18251-18260

Read Online

ABSTRACT: Red-light responsiveness of photoswitches is a highly desired property for many important application areas such as biology or material sciences. The main approach to elicit this property uses strategic substitution of long-known photoswitch motives such as azobenzenes or diarylethenes. Only very few photoswitches possess inherent red-light absorption of their core chromophore structures. Here, we present a strategy to convert the long-known purple indirubin dye into a prolific red-lightresponsive photoswitch. In a supramolecular approach, its photochromism can be changed from a negative to a positive one, while at the same time, significantly higher yields of the metastable E-isomer are obtained upon irradiation. $E$ - to $Z$ photoisomerization can then also be induced by red light of longer

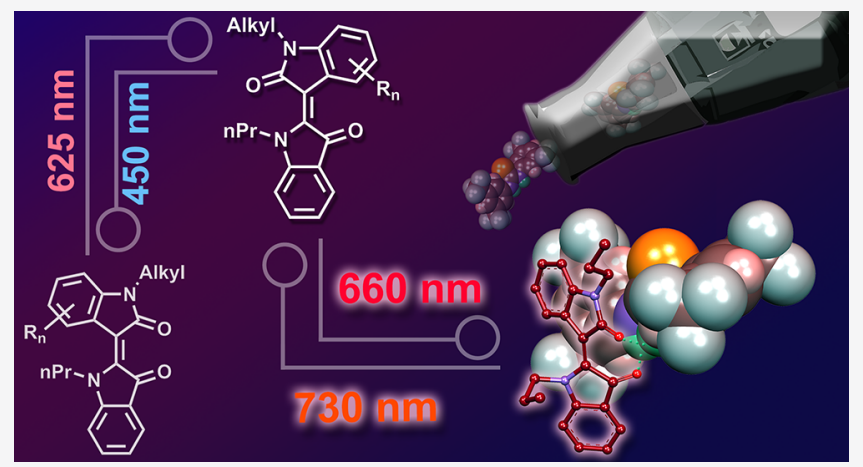
wavelengths. Indirubin therefore represents a unique example of reversible photoswitching using entirely red light for both switching directions.

\section{INTRODUCTION}

Photoswitches have gained strong traction as a molecular basis for responsive behavior at the smallest scales. The most prominent photoswitches, stilbenes, azobenzenes, spiropyranes, and diarylethenes, have already led to countless applications and uses in fields spanning the molecular, material, or biomedical sciences. They represent fundamental switching units for synthetic molecular machines, ${ }^{1-10}$ photopharmacology, ${ }^{11-16}$ light-controlled catalysts, ${ }^{17-24}$ or materials research $^{25-30}$ to name only a few examples. In their wake, a number of novel molecular photoswitch architectures have been developed, ${ }^{31}$ which bring a suite of different geometrical and electronic changes to the table, greatly expanding the toolbox of molecular engineering. Important examples are azo$\mathrm{BF}_{2}{ }^{32}$ and hydrazone-based switches, ${ }^{33,34}$ Stenhouse dyes, $^{35-37}$ imines, ${ }^{9,38,39}$ or imidazole-based biradicals. ${ }^{40}$ Indigoid dyes ${ }^{41-45}$ and foremost hemithioindigo (HTI $)^{46}$ have emerged as a very promising class of chromophores for photoswitching applications. HTI has been employed as a photopharmacological tool, ${ }^{47-50}$ for responsive supramolecular systems, ${ }^{51-54}$ catalysis, ${ }^{24}$ and advanced molecular machine building. ${ }^{10,55-61}$ The fundamental photochemistry of indigoid photoswitches has been explored in some detail, establishing rational design principles to consciously manipulate their properties. ${ }^{58,62-67}$ Different to most other photoswitch motives, indigoid core chromophores are highly colored, enabling visible-light photoswitching in both switching directions. Such low-energy absorption properties are especially important in the context of materials, biological applications, as well as generating more complex integrated molecular behavior., ${ }^{5,19,21,24}$ For biological applications, two aspects are crucial in this regard: selectivity for addressing only the photoswitch in the presence of a biological material, which itself absorbs up to the visible range, and penetration of the irradiating light into tissue, which is optimal at the "biooptical window" between 650 and $850 \mathrm{~nm}^{11,15}$ In catalysis and materials research, the photoswitching capacity again has to be compatible with catalysts, reactants, products, or other components of functional materials. Red-light responsiveness is therefore a critical property in these fields and beyond if additional control via light irradiation is to be implemented. ${ }^{25,26,28}$ Despite many efforts to shift light responsiveness of established photoswitches to the low-energy red part of the electromagnetic spectrum, ${ }^{68-72}$ there is still an urgent need for simple and effective strategies enabling proficient visible and especially red-light photoswitching.

Indirubin is a constitutional isomer of indigo and has been known as a colorant for a long time. More than 150 years ago, its synthesis was described as a side product in the synthesis of indigo by Baeyer and Emmerling. ${ }^{73}$ It is a compound of

Received: August 5, 2021

Published: October 19, 2021 


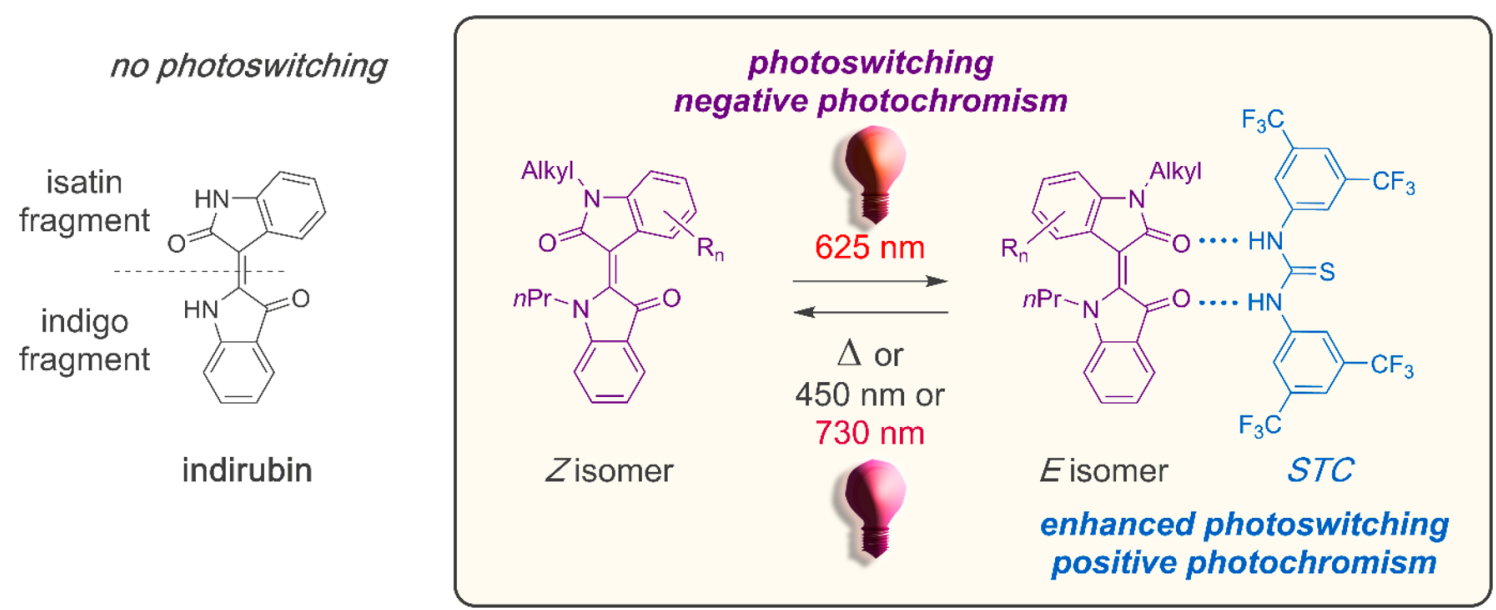

Figure 1. Red-light (only) responsive photoswitching of $N$-alkylated indirubin and improvement of photoisomerization upon supramolecular complexation by Schreiner's thiourea organocatalyst (STC).

deep purple color that is produced in bacterial metabolism ${ }^{74}$ and has been used in traditional Chinese medicine for hundreds of years. It possesses anticancer activity as well as antiangiogenesis and anti-inflammatory effects. ${ }^{75}$ Despite its prominence and vivid color, the possibility of photoisomerization of indirubin has to the best of our knowledge not been explored so far. In this work, we show that indirubin can be rendered into a red-light-responsive photoswitch by substituting the acidic $\mathrm{NH}$ protons with alkyl substituents (Figure 1).

Due to its rather moderate photochromism and particular quantum yields, isomer enrichment is however not very high in the photostationary states (pss) and reaches up to $46 \% \mathrm{E}$ isomer in toluene solution or $62 \%$ in $\mathrm{CH}_{2} \mathrm{Cl}_{2}$. The reverse photoreaction can be induced by blue light, as indirubin possesses negative photochromism. Full recovery of the thermodynamically stable $Z$-isomer can additionally be achieved thermally. This promising photoswitching behavior can significantly be improved with a straightforward supramolecular strategy. After commercially available Schreiner's thiourea organocatalyst (STC) $)^{76}$ is added, the photoswitching capacity of indirubin under red-light illumination is significantly enhanced. Selective binding of STC to the E-isomeric indirubin state leads to a pronounced red-shift of its absorption and thus to an actual reversal of the intrinsic negative photochromism into a positive one. Now up to $84 \%$ E-isomer is formed upon $625-650 \mathrm{~nm}$ irradiation and the reverse $E$ to $Z$ photoisomerization can be induced even with $730 \mathrm{~nm}$ light. Taken together, this simple implementation of supramolecular photoisomerization control allows to establish efficient and red-light-only responsiveness for an easy-toprepare and -functionalize novel photoswitch motive.

\section{RESULTS AND DISCUSSION}

In this study, different indirubin derivatives $\mathbf{1 - 5}$ are investigated with respect to their photoswitching properties (Figure 2a). Their synthesis proceeds in two steps, condensation of (substituted) isatin with indoxyl acetate and subsequent alkylation of both nitrogen atoms, either concomitantly or sequentially with the first alkylation taking place at the isatin fragment. Synthesis of substituted isatins started from commercially available 5,6-difluorinated isatin, which undergoes selective nucleophilic aromatic substitution at the 6-position. Details of the synthesis are given in the
Supporting Information. For differently substituted indirubins 1c, 2c, 3a, 4a, 5a, and $5 \mathbf{b}$ in their $Z$-isomeric state, single crystals suitable for X-ray structural analysis were obtained (Figure 2b,c), evidencing the molecular structures directly.

After the synthesis of indirubins 1-5 was established, their thermal behavior was investigated first. For all indirubin derivatives, the $Z$-isomeric state is the thermodynamically most stable one, which is exclusively populated at ambient temperatures. After $Z$ - to E-photoisomerization has taken place for the dialkylated derivatives $\mathbf{1 a - 5 a}$, the reverse thermal $E$ - to $Z$-isomerization could be followed in the dark in either toluene $\left(-d_{8}\right)$ or $\mathrm{CD}_{2} \mathrm{Cl}_{2} / \mathrm{CH}_{2} \mathrm{Cl}_{2}$ solution using ${ }^{1} \mathrm{H}$ NMR or UV/vis spectroscopy. The obtained Gibbs energies of activation $\Delta G^{\ddagger}$ are similar for the indirubins studied and range between $20.3-22.7 \mathrm{kcal} / \mathrm{mol}$, corresponding to halflives $\tau_{1 / 2}$ of the metastable $E$-isomers of $2.6 \mathrm{~min}-2.7 \mathrm{~h}$ at 20 ${ }^{\circ} \mathrm{C}$. Interestingly the thermal $E$ - to $Z$-isomerization of indirubin $\mathbf{1 a}$ is significantly dependent on the concentration in solution. If the concentration is increased by a factor of about 100 ( 2.6 versus $0.028 \mathrm{mmol} \mathrm{L}^{-1}$ ) in toluene solution, the Gibbs energy of activation $\Delta G^{\ddagger}$ is reduced by $1.4 \mathrm{kcal} /$ mol. Although dilution experiments did not hint at significant aggregation, comparison with the behavior of indirubin $\mathbf{2 a}$ points in this direction. Indirubin $2 \mathrm{a}$ bears a branched alkyl chain at the isatin $\mathrm{N}$-atom, which is expected to increase solubility and reduce self-aggregation. In this case, the concentration effects on the thermal $E$ - to $Z$-isomerization are significantly subdued, and the Gibbs energy of activation $\Delta G^{\ddagger}$ is reduced by only $0.7 \mathrm{kcal} / \mathrm{mol}$ upon a 100 -fold $(2.5$ versus $0.025 \mathrm{mmol} \mathrm{L}^{-1}$ ) concentration increase. With these $\Delta G^{\ddagger}$ values and resulting thermal stabilities of the $E$ configured metastable isomers, indirubins are fully addressable at ambient conditions.

The photochemistry of dialkylated indirubins 1a-5a (Figure 3) was investigated next using a combination of $\mathrm{UV} /$ vis absorption and NMR spectroscopy in conjunction with a comprehensive theoretical assessment. The obtained quantitative experimental data are summarized in Table 1. All derivatives show pronounced absorptions in solution with maxima close to or beyond $600 \mathrm{~nm}$, which makes them appear blue to the human eye (Figure $3 \mathrm{~b}$ ). The molar absorptions at those maxima are typically in the range of $\varepsilon=10000-15000$ $\mathrm{L} \mathrm{mol}^{-1} \mathrm{~cm}^{-1}$. In more polar $\mathrm{CH}_{2} \mathrm{Cl}_{2}$, a red-shift of the absorption is observed by $4-7 \mathrm{~nm}$ with negligible effects on 
a
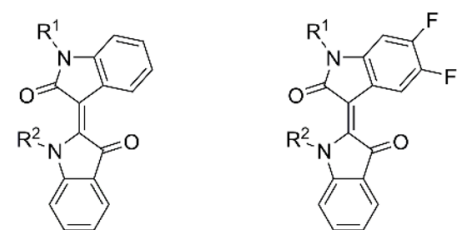

$$
\begin{aligned}
& \text { 1a } \mathrm{R}^{1}=n \mathrm{Pr} \quad \mathrm{R}^{2}=n \mathrm{Pr} \\
& \text { 1b } \mathrm{R}^{1}=\mathrm{H} \quad \mathrm{R}^{2}=\mathbf{H} \\
& \text { 1C } \mathrm{R}^{1}=n \mathrm{Pr} \mathrm{R}^{2}=\mathbf{H} \\
& \text { 2a } \mathrm{R}^{1}=3-\mathrm{Pe} \mathrm{R}^{2}=n \mathrm{Pr} \\
& \text { 2c } \mathrm{R}^{1}=3-\mathrm{Pe} \mathrm{R}^{2}=\mathrm{H}
\end{aligned}
$$

\section{b}
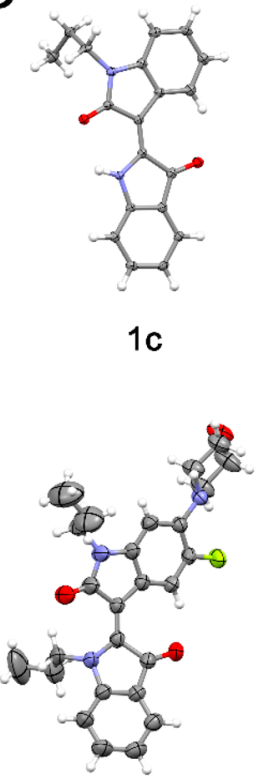

$5 a$

$3 b R^{1}=H \quad R^{2}=H$

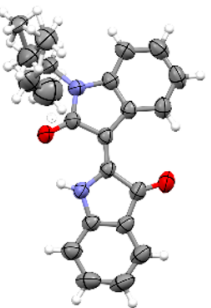

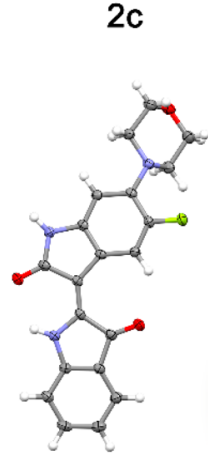

$5 b$

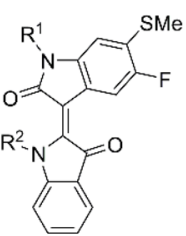

4a $\mathrm{R}^{1}=n \mathrm{Pr} \quad \mathrm{R}^{2}=n \mathrm{Pr}$

4b $R^{1}=H \quad R^{2}=H$

$$
\text { Ab } R^{1}=H^{2} \quad R^{2}=H
$$

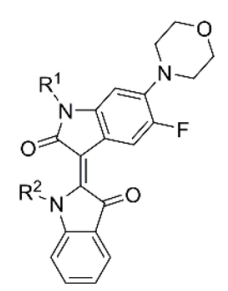

5a $\mathrm{R}^{1}=n \mathrm{Pr} \quad \mathrm{R}^{2}=n \mathrm{Pr}$

$5 b R^{1}=H \quad R^{2}=H$

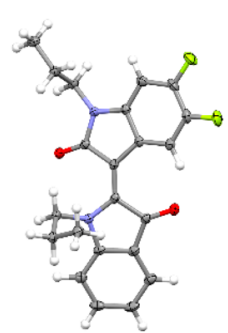

2c
$3 a$

C

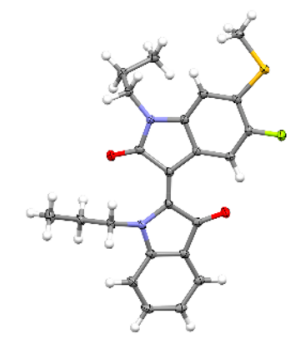

$4 a$
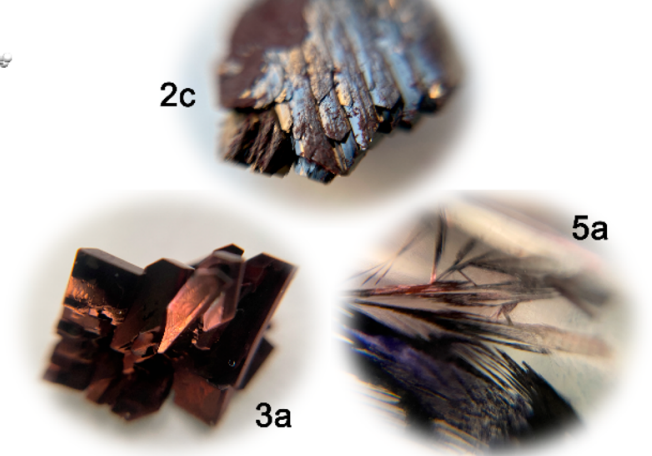

Figure 2. Indirubin derivatives investigated in this study. (a) Molecular structures of indirubines $\mathbf{1}-\mathbf{5}$ in their thermodynamically most stable $Z$ isomeric form. (b) Structures of $Z$-isomeric indirubins 1c, 2c, 3a, 4a, 5a, and $\mathbf{5 b}$ in the crystalline state. Structures are shown as ellipsoids with $50 \%$ probability. (c) Photographs of the crystals of indirubins Z-2c, Z-3a, and Z-5a.

the molar absorption values. When comparing the absorptions of dialkylated with unsubstituted indirubin, a noticeable redshift of $54 \mathrm{~nm}$ is observed for the absorption of the former. This red-shifted absorption is reproduced in the theoretical description and can be attributed to the electron donation properties of the alkyl substituents at the nitrogen atoms.

Upon irradiation with different wavelengths of light, no spectral changes are observed for unsubstituted indirubin $\mathbf{1 c}$ at ambient temperatures under continuous irradiation. This behavior resembles the behavior of unsubstituted indigo, which undergoes a very rapid excited-state proton transfer (ESPT) that outcompetes the slower photoisomerization processes. ${ }^{77}$ Upon replacement of at least one $\mathrm{NH}$ proton of indigo by carbon-based substituents, reversible photoswitching is observed, since no (efficient) ESPT can take place in these cases. ${ }^{44,45,78}$ In a related approach, we show here that replacement of both $\mathrm{NH}$ protons of indirubin by alkyl substituents $(\mathbf{1} \mathbf{a}-\mathbf{5 a})$ allows photoisomerization behavior to be elicited. If, however, only the $\mathrm{NH}$ proton of the isatin fragment is replaced by alkyl substituents in, for example, 1c, again no photoisomerization is observed at ambient temperatures under steady-state irradiation. This behavior strongly suggests that the $\mathrm{NH}$ proton of the indigo fragment is a crucial feature inhibiting productive photoswitching of indirubins.

For dialkylated indirubins $\mathbf{1 a - 5 a} Z$ - to E-photoisomerization takes place upon $625 \mathrm{~nm}$ irradiation, leading to a reduction of the maximum at around $600 \mathrm{~nm}$ and a blue-shift of the absorption (see Figure $3 \mathrm{a}$ and the Supporting Information). This behavior establishes negative photochromism for indirubins. At the same time, absorption increases at around $450 \mathrm{~nm}$. Despite a sizable photochromism in toluene solution, photoisomerization does not lead to a very strong accumulation of the metastable E-isomer in the pss. This can be explained by the higher quantum yield for the "backwards" $E$ - to $Z$-photoisomerization $\left(\phi_{E / Z}=1.8 \%\right)$ as opposed to the opposite $Z$ - to $E$-photoisomerization $\left(\phi_{Z / E}=0.8 \%\right)$. As judged by NMR spectroscopy, between $24 \%$ (indirubin $5 \mathrm{a}$ ) and $46 \%$ (indirubin 1a) of E-isomer is obtained upon $625 \mathrm{~nm}$ irradiation in toluene- $d_{8}$. When changing the solvent to the 

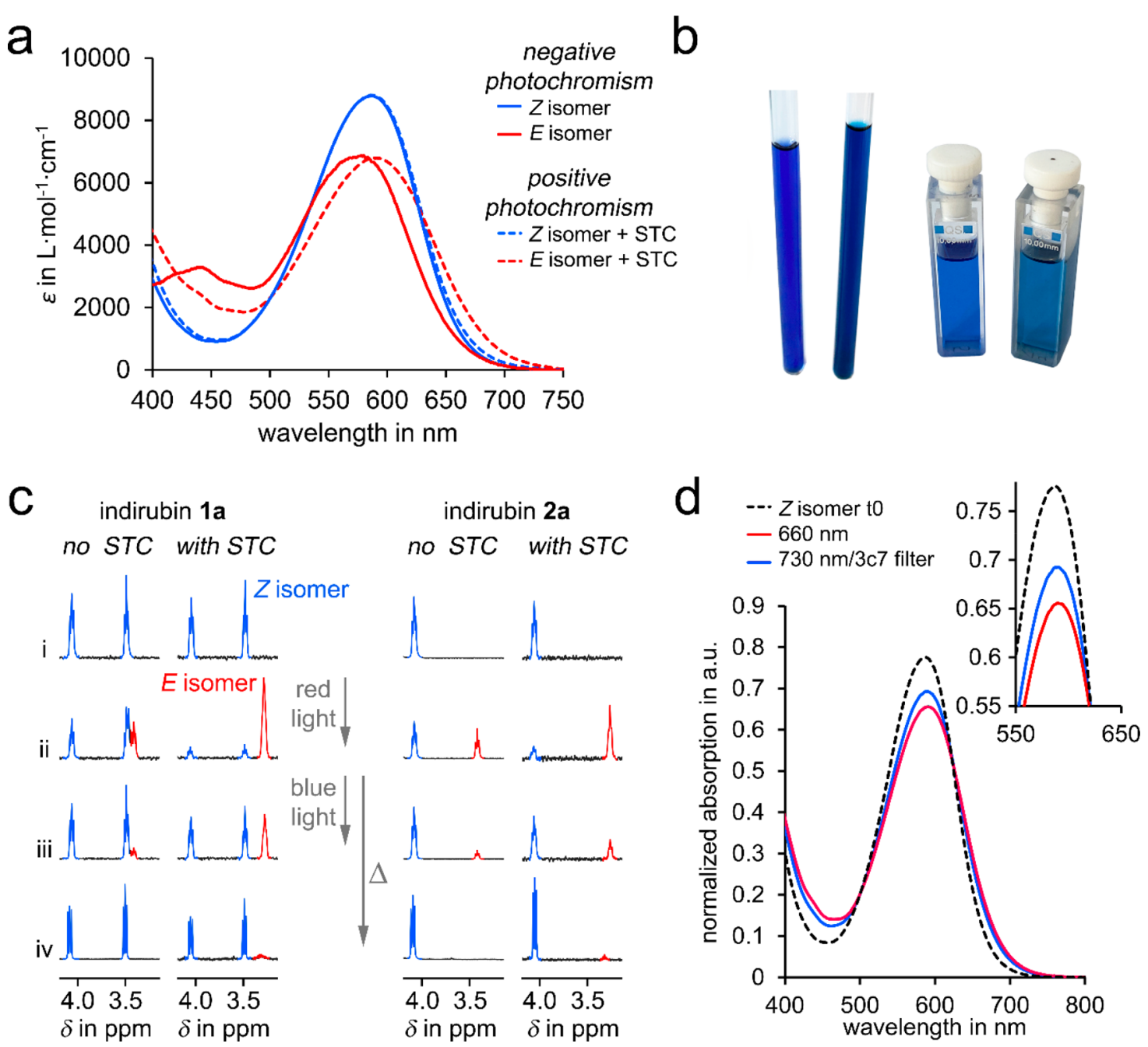

Figure 3. Photoswitching of indirubins and supramolecular control thereof. (a) Molar absorption coefficients of the $Z$ - and $E$-isomers of indirubin $\mathbf{2 a}$ in the absence (solid lines) and presence (dotted lines) of STC. Molar absorptions of the respective E-isomers are obtained from measuring the absorption of an E-enriched solution and subtracting the spectral components of the remaining Z-isomer. (b) Photographs of toluene- $d_{8}$ solutions of indirubin 5a irradiated to the pss with $625 \mathrm{~nm}$ light. Solutions for NMR and UV/vis measurements are shown in the absence (left tube/cuvette) and in presence (right tube/cuvette) of STC. (c) Indicative sections of ${ }^{1} \mathrm{H} \mathrm{NMR}$ spectra $\left(400 \mathrm{MHz}\right.$, i-iii $0{ }^{\circ} \mathrm{C}$, iv $20{ }^{\circ} \mathrm{C}$, toluene$d_{8}$ ) showing the switching capacity of indirubins 1a and 2a in the absence or presence of STC. (i) Initially only Z-isomers are present; (ii) after irradiation with $625 \mathrm{~nm}$ light to the pss; (iii) after irradiation with $450 \mathrm{~nm}$ light to the pss; (iv) after thermal $E$ - to Z-isomerization. (d) UV/vis absorption spectra of toluene solution of 2 a showing reversible photoswitching with two shades of red.

more polar $\mathrm{CH}_{2} \mathrm{Cl}_{2} / \mathrm{CD}_{2} \mathrm{Cl}_{2}$, photochswitching is enhanced. As a result, higher $E$-isomer accumulations are achieved in the pss in this solvent ranging from $27 \%$ (indirubin 5a) to $62 \%$ (indirubin 1a). Because of the increased absorption at 450 $\mathrm{nm}, E$ - to $Z$-photoisomerization can be induced by blue light of this wavelength, which restores high $Z$-isomer content in the range of $83 \%$ (indirubin 1a) to $90 \%$ (indirubin $\mathbf{5 a}$ ) in the pss in toluene solution. The photoswitching is highly reversible, showing only a miniscule deterioration of the performance after 10 full switching cycles (see Supporting Information). In $\mathrm{CH}_{2} \mathrm{Cl}_{2} / \mathrm{CD}_{2} \mathrm{Cl}_{2}$, a similar behavior is observed. In this way, reversible photoswitching using red $(625$ or $660 \mathrm{~nm})$ and blue $(450 \mathrm{~nm})$ light is possible with alkylated indirubins. Quantitative reversion of the metastable $E$ - to the $Z$-isomeric state is possible thermally for all derivatives.

Although dialkylated indirubins showed already sizable redlight-induced photoisomerization capacity, there was still room to improve the photoswitching especially with regard to accumulation of metastable E-isomers in the pss. Typically, substitution approaches are followed for this purpose. However, it became quickly apparent that substitution changes at the isatin fragment were not very effective, as all dialkylated derivatives $\mathbf{1 a - 5 a}$ provided a similar photoswitching capacity. We therefore tested a different approach, which relies on supramolecular interactions with an external hydrogen bond donor. A similar idea has been introduced recently to influence the thermal isomerizations of Stenhouse adduct (DASA) photoswitches, ${ }^{79}$ but to the best of our knowledge, no strongly beneficiary effects in the context of photoswitching have been shown so far (for related intramolecular hydrogen bonding effects, see, for example, refs 80-82 and for a covalently linked thiourea-Stenhouse adduct to photoswitch solubility see ref 83). Upon addition of STC, photochromism changed significantly for dialkylated indirubins $\mathbf{1 a - 5 a}$ in solution. The reason for this effect is a stronger recognition of the metastable $E$-isomer as opposed to the $Z$-isomer as evidenced by significant induced shifts of the 
Table 1. (Photo)physical and Photochemical Properties of Dialkylated Indirubins 1a-5a as Determined by ${ }^{1} \mathrm{H}$ NMR $\left({ }^{\#}\right)$ or UV/vis Absorption Spectroscopy (*)

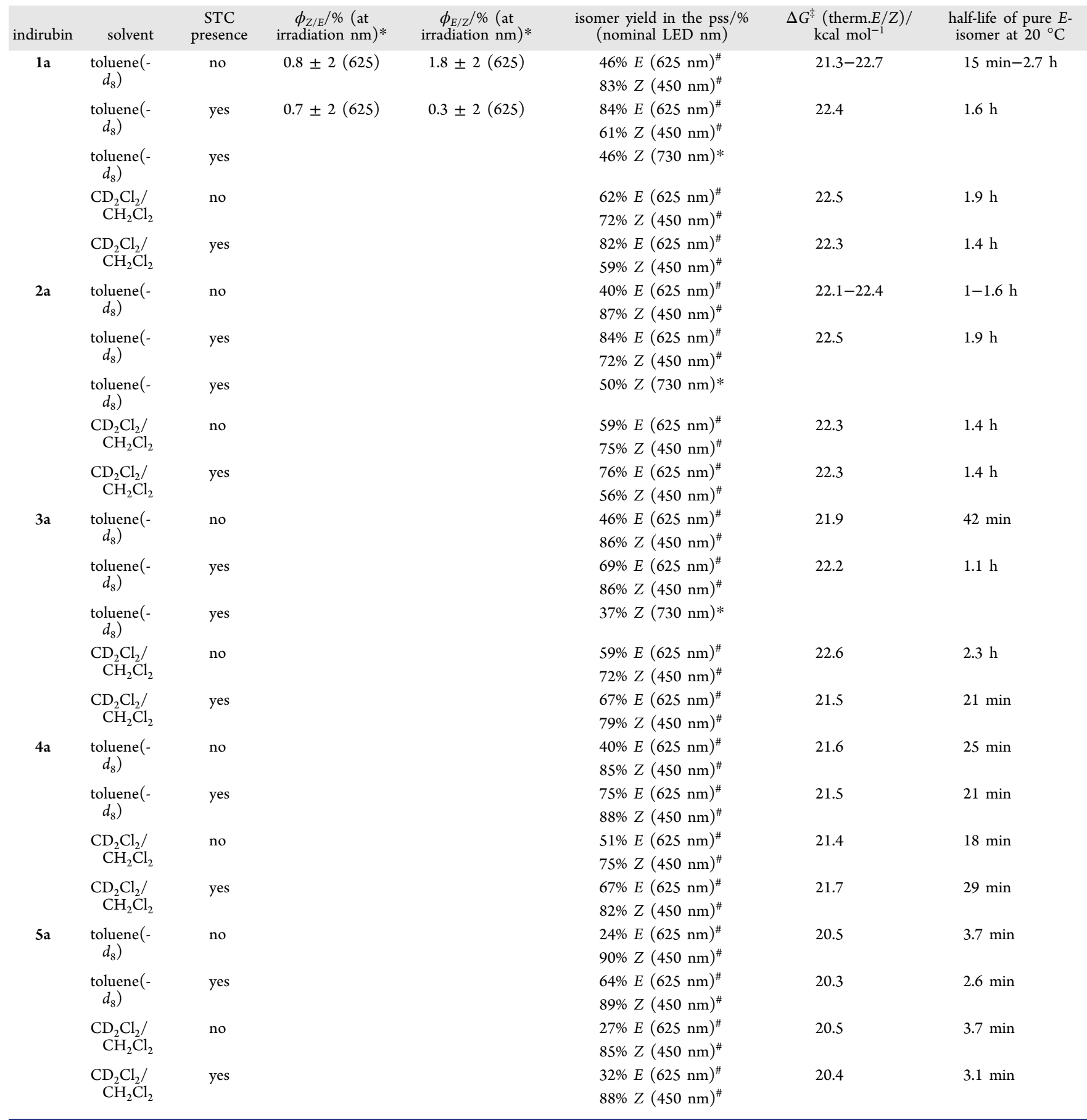

former's ${ }^{1} \mathrm{H}$ NMR signals (see Supporting Information). No significant changes for the $Z$-isomer signals were observed upon STC addition. As a result of this selective recognition, the absorption of the E-isomer is red-shifted such that the initial negative photochromism is now turned into a positive one with better spectral separation between the isomers' absorption spectra in the long-wavelength region. Additionally, the quantum yields for the two photoreactions ( $Z$ - to $E$ - and $E$ - to $Z$-photoisomerizations measured at $625 \mathrm{~nm}$ irradiation where both isomers absorb well) are changed significantly upon STC binding. Without the presence of STC, $\phi_{Z / E}=$ $0.8 \%$ and $\phi_{E / Z}=1.8 \%$; however, after addition of STC, the former remains essentially unaffected, $\phi_{Z / E}=0.7 \%$, while the latter drops to $\phi_{E / Z}=0.3 \%$. This behavior could be explained by a stabilization of the $E$-isomeric state via association with STC and a resulting hampering of productive photoisomerization. In favor of this explanation is the observation that upon heating in the dark, a maximum of $2 \% E$-isomeric indirubins $\mathbf{1 a}$ and $\mathbf{2 a}$ remains in solution in the presence of STC, while in the absence of STC, no E-isomer remains (Figure 3c). However, the kinetics of the thermal $E$ - to $Z$ isomerization is not affected by addition of STC, and the same half-lives of the respective $E$-isomers are observed in the presence or absence of STC (see Table 1 for the exact values 

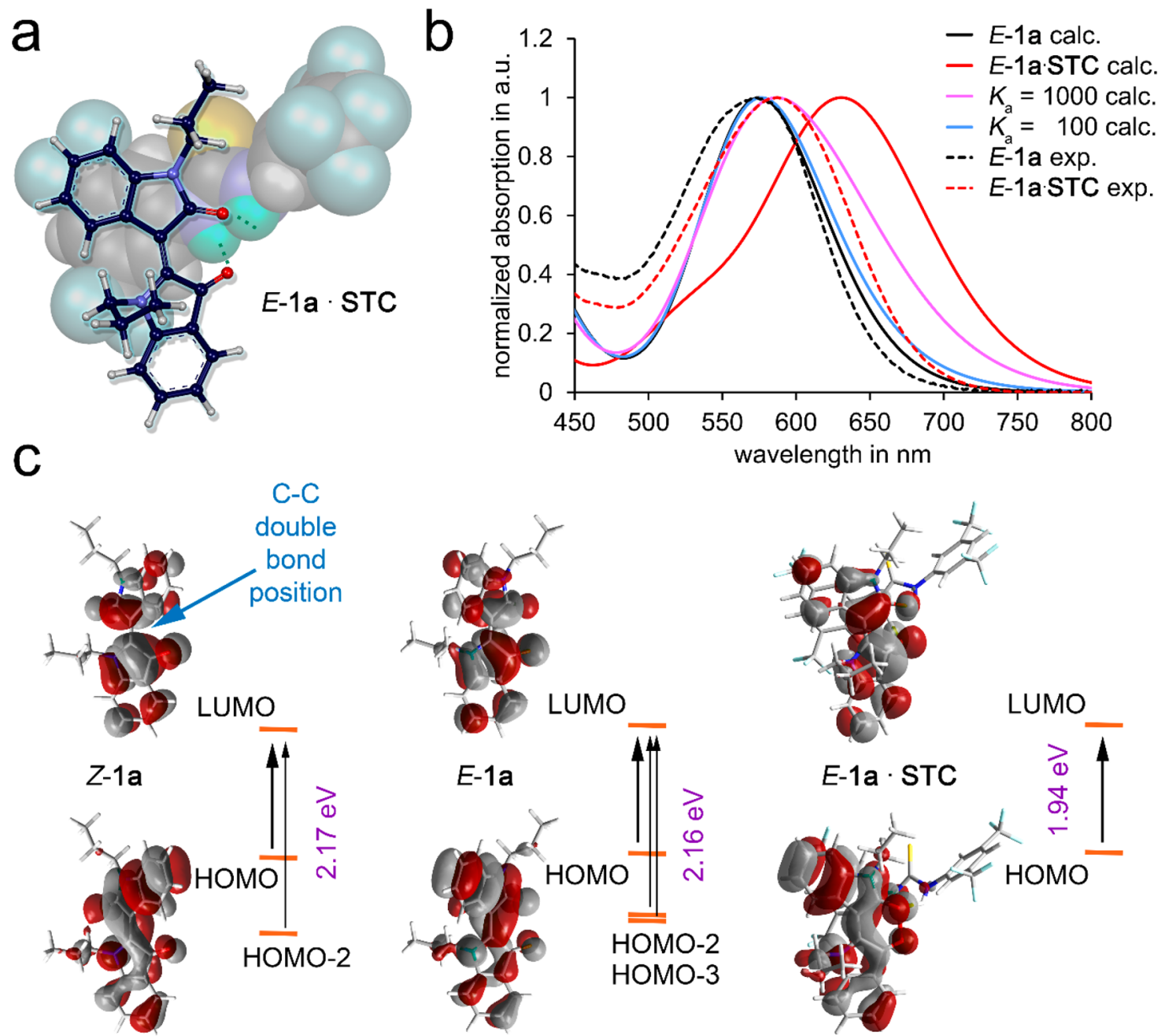

Figure 4. Theoretical description of indirubin 1a photoswitching and its supramolecular control. (a) Structure of the complex between $E$-1a and STC as optimized on the B3LYP-D3BJ/6-311++G(d,p)-PCM(tol) level of theory. (b) Calculated (PBE0/6-311+G(d,p)-PCM(tol)//B3LYP$\mathrm{D} 3 \mathrm{BJ} / 6-311 \mathrm{G}(\mathrm{d}, \mathrm{p})-\mathrm{PCM}(\mathrm{tol})$ level of theory) UV/vis absorption of E-1a (solid black line) and of the complex between E-1a and STC (solid red line, the Boltzmann-averaged spectrum of different complex structures is shown) and comparison to the corresponding experimental spectra in toluene solution (dashed black line for E-1a and dashed red line for the complex between E-1a and STC). Theoretical UV/vis absorptions taking into account two different binding constants $K_{\mathrm{a}}=1000$ (solid pink line) or $K_{\mathrm{a}}=100$ (solid blue line) are also shown. (A reference concentration of $1 \mathrm{mmol} \mathrm{L}^{-1}$ was assumed for the calculation of E-1a/E-1a-STC equilibrium ratios.) (c) Orbitals involved in the electronic excitation of Z-1a (left), E-1a (middle), and the E-1a-STC complex (right). HOMO and LUMO are depicted together with a schematic representation of the most important orbitals involved in the transition and the resulting sum-excitation energies (purple numbers).

quantified). The indifference of the thermal E-to $Z$-isomerization kinetics to the presence of STC suggests also a more direct and possibly electronic influence of the thiourea on the quantum yield. As a result of mainly the quantum yield changes, highly improved $E$-isomer enrichment in the pss at $625 \mathrm{~nm}$ irradiation (where photochromism remains mediocre) is possible in the presence of STC. From the initial 24\% (indirubin 5a) to $46 \%$ (indirubin 1a) of obtained E-isomers in toluene solution, an improvement to $64 \%$ (indirubin 5a) to $84 \%$ (indirubin 1a) can now be achieved. The reverse $E$ - to $Z$ photoisomerization can still be affected with blue light leading up to $72 \% \mathrm{Z}$-isomer enrichment despite lower quantum yields for this reaction in the presence of STC. Almost complete reversal to the $Z$-isomer ( $100 \%$ for indirubins $\mathbf{3 a}-\mathbf{5 a}$ and at least $98 \%$ for indirubins $\mathbf{1 a}$ and $\mathbf{2 a}$ ) is also still possible in all cases by a brief heating step. In $\mathrm{CH}_{2} \mathrm{Cl}_{2} / \mathrm{CD}_{2} \mathrm{Cl}_{2}$, the effects are lesser owing to the higher polarity of the surrounding solvent. However, sizable improvements are still observed for the photoswitching in this solvent. Because of the now positive photochromism, the reverse $E$ - to $Z$-photoisomerization can also be induced with red light of longer wavelengths. For example, starting from $75 \%$ E-1a or $74 \%$ E-2a in in toluene solution irradiation with $730 \mathrm{~nm}$ light delivers $46 \%$ and $50 \%$ of the corresponding Z-1a and Z-2a isomers, respectively (Figure 3c). Therefore, reversible photoswitching with two shades of red is achieved, one of which resides close to the near-infrared (NIR) spectral region without the need for high-intensity two-photon processes or sensitizing. Because of the supramolecular nature of inducing such unusual light addressability, it is possible to use the recognition process as an additional control element. Without the thiourea, blue- and red-light responsiveness is obtained in a negatively photochromic system. In the presence of the thiourea, blue and red or dual red-light responsiveness is obtained in a positively photochromic system with the very same photoswitch. Also in this case, we observe high reversibility of the all-red-light photoswitching and no significant deterioration of the 
performance after 10 full switching cycles (see Supporting Information).

To gain deeper insights into the reason for the observed supramolecular induction of photochromism change, we conducted a theoretical study for indirubin $\mathbf{1}$ with a combination of methods, which are described in detail in the Supporting Information. First, the structures of the $Z$ - and $E$-isomers of indirubin 1a were optimized on the B3LYP/6$311 \mathrm{G}(\mathrm{d}, \mathrm{p})$ level of theory. Afterward, a preliminary screening of different supramolecular interaction geometries for the complex between E-isomeric indirubin 1a and 1 equiv of STC (other stoichiometries could not reliably be described by theory owed to the significantly increased complex size) was conducted using the MMFFs force field and the MCMM algorithm for conformational analysis implemented within the MacroModel program package of the Schroedinger suite. The variety of obtained complex structures was scrutinized for structural redundancies, and unique structures (up to 50 different conformers) were optimized first on the B3LYP$\mathrm{D} 3 \mathrm{BJ} / 6-31 \mathrm{G}(\mathrm{d})-\mathrm{PCM}$ (tol) level of theory. Afterward, again, redundant structures were discarded, and preoptimized unique structures were reoptimized with a greater basis (6-311+ $+G(d, p))$. Subsequent frequency analyses confirmed the obtained structures as minima on the potential energy hypersurface. As can be seen from Figure $4 a$, the supramolecular structure with lowest energy exhibits hydrogen bonding to STC via both carbonyl oxygen atoms of indirubin's isatin fragment. Additional aromatic interactions are observed between the aromatic surface of the upper isatin fragment and one electron-deficient aromatic fragment of STC. There are also some possible dispersive interactions occurring between the $n$-propyl chain of 1a's isatin fragment and the other aromatic fragment of STC.

TDDFT calculations allowed the corresponding theoretical $\mathrm{UV} /$ vis absorption spectra to be obtained for the isolated indirubins Z-1a (see Supporting Information) and E-1a as well as for the complex between E-1a and STC (Figure 4b). In each case, 10 states were taken into account to describe the absorption. When comparing the absorption of Z-1a and E-1a, almost no difference in the overall transition energies is observed, which is in general agreement with the experimentally observed small negative photochromism. However, a full account of negative photochromism is not found in the theoretical description of the pure indirubin structures. For both isomers, $Z-1 \mathbf{a}$ and $E-\mathbf{1 a}$, the main contribution to the absorption stems from a HOMO-LUMO transition, which can roughly be described as a $\pi-\pi^{*}$ transition (Figure $4 \mathrm{c}$ ). Here, the double-bond character of the central isomerizable double bond is lost upon transition to the LUMO, which is a prerequisite for indirubin photoswitching capacity. Nevertheless, there are significant contributions of lower-lying orbitals such as HOMO-2 or HOMO-3. The absorption of the complex between E-1a and STC is found to be strongly red-shifted as compared to $E$-1a alone, which reproduces the experimentally observed positive photochromism. When taking into account different possible binding constants for complex formation (Figure $4 \mathrm{~b}$ ), the experimentally observed spectral shifts are reproduced well for binding constants ranging between 100 and $1000 \mathrm{M}^{-1}$. For the E-1a-STC complex, the HOMO-LUMO $\pi-\pi^{*}$ transition in indirubin is more dominant as a result of the hydrogen bonding interaction with STC, which explains why the photochromism now is positive (Figure 4c). Such a supramolecular influence of the environment on photoswitching is frequently used in biological systems to tune photochemical properties as most eminent for retinal photoswitching (see for example ref 84). Different to many natural systems (e.g., in natural retinal ${ }^{85}$ or bilin $^{86}$ ) however, the mechanism at hand does not involve a pronounced twisting of the chromophore structure by the supramolecular interaction. Instead, polarity changes and polarization play a more crucial role here.

In summary, we present indirubin as versatile red-lightresponsive photoswitch together with an effective supramolecular strategy to significantly enhance its photoresponse. Alkylation of the $\mathrm{NH}$ protons was found to be a fundamental prerequisite to elicit photoswitching capacity and negative photochromism in the first place. Up to $62 \%$ of the metastable $E$-isomer was obtained for alkylated indirubins when irradiating with $625 \mathrm{~nm}$ red light, and up to $90 \%$ of the Zisomer is accumulated upon $450 \mathrm{~nm}$ blue-light irradiation. After addition of the hydrogen bonding STC, the photochemistry of indirubin is improved significantly via supramolecular interactions. Up to $84 \%$ of the $E$-isomer is now obtained upon $625 \mathrm{~nm}$ irradiation, while at the same time, the negative photochromism is turned into a positive one. The latter makes it possible to use a different wavelength of red light, i.e., $730 \mathrm{~nm}$, to induce the reverse $E$ - to $Z$ photoisomerization. As a result, indirubins can be photoswitched with two shades of red light, a highly sought-after responsiveness for many applications. Conversion back to the $Z$-isomer is also achieved thermally in all cases. These results open up a new structural space for low-energy light-driven photoisomerization reactions of double bonds within a rigid and geometrically well-defined molecular framework. The advantage of a supramolecular approach is compatibility with a variety of different photoswitches (either the same class as shown in this work or in different classes, which we will explore in the future) without the need for additional substitution approaches on the photoswitch itself to adjust its light response. Future elaboration of the herein presented supramolecular principle by, for example, flexible covalent attachment of STC to indirubin, will allow the observed beneficiary effects to be significantly increased, which will be of importance for, for example, biological applications requiring high dilutions and competitive environments. Applications in responsive molecular and supramolecular systems are currently under investigation in our laboratory and will be reported in due course.

\section{ASSOCIATED CONTENT}

\section{Supporting Information}

The Supporting Information is available free of charge at https://pubs.acs.org/doi/10.1021/jacs.1c08206.

Details of synthesis, photochemical, photophysical, and thermal behavior, theoretical description, supramolecular interactions, crystal structural data. Additional theoretically obtained optimized structures on different levels of theory are available by request from the authors (PDF)

\section{Accession Codes}

CCDC 2100391-2100396 contain the supplementary crystallographic data for this paper. These data can be obtained free of charge via www.ccdc.cam.ac.uk/data_request/cif, or by emailing data_request@ccdc.cam.ac.uk, or by contacting The 
Cambridge Crystallographic Data Centre, 12 Union Road, Cambridge CB2 1EZ, UK; fax: +44 1223336033.

\section{AUTHOR INFORMATION}

\section{Corresponding Author}

Henry Dube - Friedrich-Alexander Universität Erlangen-

Nürnberg, Department of Chemistry and Pharmacy, 91058

Erlangen, Germany; $\odot$ orcid.org/0000-0002-5055-9924;

Email: henry.dube@fau.de

\section{Authors}

Stefan Thumser - Friedrich-Alexander Universität ErlangenNürnberg, Department of Chemistry and Pharmacy, 91058 Erlangen, Germany

Laura Köttner - Friedrich-Alexander Universität ErlangenNürnberg, Department of Chemistry and Pharmacy, 91058 Erlangen, Germany

Nadine Hoffmann - Ludwig-Maximilians Universität München, Department of Chemistry and Center for Integrated Protein Science CIPSM, 81377 Munich, Germany

Peter Mayer - Ludwig-Maximilians Universität München, Department of Chemistry and Center for Integrated Protein Science CIPSM, 81377 Munich, Germany

Complete contact information is available at: https://pubs.acs.org/10.1021/jacs.1c08206

\section{Notes}

The authors declare no competing financial interest.

\section{ACKNOWLEDGMENTS}

H. Dube thanks the Deutsche Forschungsgemeinschaft (DFG) for an Emmy Noether fellowship (DU 1414/1-2). We further thank the Deutsche Forschungsgemeinschaft (SFB 749, A12) and the Cluster of Excellence "Center for Integrated Protein Science Munich” (CIPSM) for financial support. This project has also received funding from the European Research Council (ERC) under the European Union's Horizon 2020 research and innovation programme (PHOTOMECH, grant agreement No 101001794).

\section{REFERENCES}

(1) Koumura, N.; Zijlstra, R. W. J.; van Delden, R. A.; Harada, N.; Feringa, B. L. Light-driven monodirectional molecular rotor. Nature 1999, 401, 152-155.

(2) Kistemaker, H. A.; Stacko, P.; Visser, J.; Feringa, B. L. Unidirectional rotary motion in achiral molecular motors. Nat. Chem. 2015, 7, 890-896.

(3) Boursalian, G. B.; Nijboer, E. R.; Dorel, R.; Pfeifer, L.; Markovitch, O.; Blokhuis, A.; Feringa, B. L. All-Photochemical Rotation of Molecular Motors with a Phosphorus Stereoelement. J. Am. Chem. Soc. 2020, 142 (39), 16868-16876.

(4) Barrell, M. J.; Campana, A. G.; von Delius, M.; Geertsema, E. M.; Leigh, D. A. Light-driven transport of a molecular walker in either direction along a molecular track. Angew. Chem., Int. Ed. 2011, 50 (1), 285-290.

(5) Erbas-Cakmak, S.; Leigh, D. A.; McTernan, C. T.; Nussbaumer, A. L. Artificial Molecular Machines. Chem. Rev. 2015, 115 (18), 10081-10206.

(6) Baroncini, M.; Silvi, S.; Credi, A. Photo- and Redox-Driven Artificial Molecular Motors. Chem. Rev. 2020, 120, 200-268.

(7) Ragazzon, G.; Baroncini, M.; Silvi, S.; Venturi, M.; Credi, A. Light-powered autonomous and directional molecular motion of a dissipative self-assembling system. Nat. Nanotechnol. 2015, 10, 7075.
(8) Haberhauer, G. A molecular four-stroke motor. Angew. Chem., Int. Ed. 2011, 50 (28), 6415-6418.

(9) Greb, L.; Eichhofer, A.; Lehn, J. M. Synthetic Molecular Motors: Thermal $\mathrm{N}$ Inversion and Directional Photoinduced $\mathrm{CN}$ Bond Rotation of Camphorquinone Imines. Angew. Chem., Int. Ed. 2015, 54, 14345-14348.

(10) Guentner, M.; Schildhauer, M.; Thumser, S.; Mayer, P.; Stephenson, D.; Mayer, P. J.; Dube, H. Sunlight-powered $\mathrm{kHz}$ rotation of a hemithioindigo-based molecular motor. Nat. Commun. 2015, 6, 8406.

(11) Hull, K.; Morstein, J.; Trauner, D. In Vivo Photopharmacology. Chem. Rev. 2018, 118 (21), 10710-10747.

(12) Frank, J. A.; Broichhagen, J.; Yushchenko, D. A.; Trauner, D.; Schultz, C.; Hodson, D. J. Optical tools for understanding the complexity of $\beta$-cell signalling and insulin release. Nat. Rev. Endocrinol. 2018, 14 (12), 721-737.

(13) Leippe, P.; Broichhagen, J.; Cailliau, K.; Mougel, A.; Morel, M.; Dissous, C.; Trauner, D.; Vicogne, J. Transformation of Receptor Tyrosine Kinases into Glutamate Receptors and Photoreceptors. Angew. Chem., Int. Ed. 2020, 59 (17), 6720-6723.

(14) Borowiak, M.; Nahaboo, W.; Reynders, M.; Nekolla, K.; Jalinot, P.; Hasserodt, J.; Rehberg, M.; Delattre, M.; Zahler, S.; Vollmar, A.; Trauner, D.; Thorn-Seshold, O. Photoswitchable Inhibitors of Microtubule Dynamics Optically Control Mitosis and Cell Death. Cell 2015, 162 (2), 403-411.

(15) Lerch, M. M.; Hansen, M. J.; van Dam, G. M.; Szymanski, W.; Feringa, B. L. Emerging Targets in Photopharmacology. Angew. Chem., Int. Ed. 2016, 55 (37), 10978-10999.

(16) Albert, L.; Vazquez, O. Photoswitchable peptides for spatiotemporal control of biological functions. Chem. Commun. 2019, 55 (69), 10192-10213.

(17) Ueno, A.; Takahashi, K.; Osa, T. Photoregulation of catalytic activity of $\beta$-cyclodextrin by an azo inhibitor. J. Chem. Soc., Chem. Commun. 1980, No. 17, 837-838.

(18) Eisenreich, F.; Kathan, M.; Dallmann, A.; Ihrig, S. P.; Schwaar, T.; Schmidt, B. M.; Hecht, S. A photoswitchable catalyst system for remote-controlled (co)polymerization in situ. Nat. Catal. 2018, 1 (7), 516-522.

(19) Göstl, R.; Senf, A.; Hecht, S. Remote-controlling chemical reactions by light: Towards chemistry with high spatio-temporal resolution. Chem. Soc. Rev. 2014, 43 (6), 1982-1996.

(20) Wang, J.; Feringa, B. L. Dynamic control of chiral space in a catalytic asymmetric reaction using a molecular motor. Science 2011 331 (6023), 1429-1432.

(21) Dorel, R.; Feringa, B. L. Photoswitchable catalysis based on the isomerisation of double bonds. Chem. Commun. 2019, 55 (46), 6477-6486.

(22) Pizzolato, S. F.; Štacko, P.; Kistemaker, J. C. M.; van Leeuwen, T.; Feringa, B. L. Phosphoramidite-based photoresponsive ligands displaying multifold transfer of chirality in dynamic enantioselective metal catalysis. Nat. Catal. 2020, 3 (6), 488-496.

(23) Neilson, B. M.; Bielawski, C. W. Photoswitchable organocatalysis: using light to modulate the catalytic activities of $\mathrm{N}$ heterocyclic carbenes. J. Am. Chem. Soc. 2012, 134 (30), 1269312699.

(24) Grill, K.; Dube, H. Supramolecular Relay-Control of Organocatalysis with a Hemithioindigo-Based Molecular Motor. J. Am. Chem. Soc. 2020, 142 (45), 19300-19307.

(25) Boelke, J.; Hecht, S. Designing Molecular Photoswitches for Soft Materials Applications. Adv. Opt. Mater. 2019, 7 (16), 1900404.

(26) Telitel, S.; Blasco, E.; Bangert, L. D.; Schacher, F. H.; Goldmann, A. S.; Barner-Kowollik, C. Photo-reversible bonding and cleavage of block copolymers. Polym. Chem. 2017, 8 (27), 40384042.

(27) Orlova, T.; Lancia, F.; Loussert, C.; Iamsaard, S.; Katsonis, N.; Brasselet, E. Revolving supramolecular chiral structures powered by light in nanomotor-doped liquid crystals. Nat. Nanotechnol. 2018, 13, 304-308. 
(28) Foy, J. T.; Li, Q.; Goujon, A.; Colard-Itte, J.-R.; Fuks, G.; Moulin, E.; Schiffmann, O.; Dattler, D.; Funeriu, D. P.; Giuseppone, $\mathrm{N}$. Dual-light control of nanomachines that integrate motor and modulator subunits. Nat. Nanotechnol. 2017, 12, 540-545.

(29) Li, Q.; Fuks, G.; Moulin, E.; Maaloum, M.; Rawiso, M.; Kulic, I.; Foy, J. T.; Giuseppone, N. Macroscopic contraction of a gel induced by the integrated motion of light-driven molecular motors. Nat. Nanotechnol. 2015, 10, 161-165.

(30) Montero de Espinosa, L.; Meesorn, W.; Moatsou, D.; Weder, C. Bioinspired Polymer Systems with Stimuli-Responsive Mechanical Properties. Chem. Rev. 2017, 117 (20), 12851-12892.

(31) Harris, J. D.; Moran, M. J.; Aprahamian, I. New molecular switch architectures. Proc. Natl. Acad. Sci. U. S. A. 2018, 115, 94149422.

(32) Yang, Y.; Hughes, R. P.; Aprahamian, I. Near-infrared light activated azo-BF2 switches. J. Am. Chem. Soc. 2014, 136 (38), 13190-13193.

(33) Li, Q.; Qian, H.; Shao, B.; Hughes, R. P.; Aprahamian, I. Building Strain with Large Macrocycles and Using It To Tune the Thermal Half-Lives of Hydrazone Photochromes. J. Am. Chem. Soc. 2018, 140 (37), 11829-11835.

(34) Shao, B.; Aprahamian, I. Hydrazones as New Molecular Tools. Chem. 2020, 6 (9), 2162-2173.

(35) Helmy, S.; Leibfarth, F. A.; Oh, S.; Poelma, J. E.; Hawker, C. J.; Read de Alaniz, J. Photoswitching using visible light: a new class of organic photochromic molecules. J. Am. Chem. Soc. 2014, 136 (23), $8169-8172$.

(36) Hemmer, J. R.; Poelma, S. O.; Treat, N.; Page, Z. A.; Dolinski, N.; Diaz, Y. J.; Tomlinson, W.; Clark, K. D.; Hooper, J. P.; Hawker, C. J.; Read de Alaniz, J. Tunable Visible and Near Infrared Photoswitches. J. Am. Chem. Soc. 2016, 138, 13960-13966.

(37) Zulfikri, H.; Koenis, M. A. J.; Lerch, M. M.; Di Donato, M.; Szymanski, W.; Filippi, C.; Feringa, B. L.; Buma, W. J. Taming the Complexity of Donor-Acceptor Stenhouse Adducts: Infrared Motion Pictures of the Complete Switching Pathway. J. Am. Chem. Soc. 2019, 141 (18), 7376-7384.

(38) Greb, L.; Lehn, J. M. Light-driven molecular motors: imines as four-step or two-step unidirectional rotors. J. Am. Chem. Soc. 2014, 136 (38), 13114-13117.

(39) Greb, L.; Mutlu, H.; Barner-Kowollik, C.; Lehn, J. M. Photoand Metallo-responsive N-Alkyl alpha-Bisimines as Orthogonally Addressable Main-Chain Functional Groups in Metathesis Polymers. J. Am. Chem. Soc. 2016, 138 (4), 1142-1145.

(40) Mutoh, K.; Kobayashi, Y.; Yamane, T.; Ikezawa, T.; Abe, J. Rate-Tunable Stepwise Two-Photon-Gated Photoresponsive Systems Employing a Synergetic Interaction between Transient Biradical Units. J. Am. Chem. Soc. 2017, 139 (12), 4452-4461.

(41) Petermayer, C.; Dube, H. Indigoid Photoswitches: Visible Light Responsive Molecular Tools. Acc. Chem. Res. 2018, 51 (5), $1153-1163$.

(42) Petermayer, C.; Thumser, S.; Kink, F.; Mayer, P.; Dube, H. Hemiindigo: Highly Bistable Photoswitching at the Biooptical Window. J. Am. Chem. Soc. 2017, 139 (42), 15060-15067.

(43) Petermayer, C.; Dube, H. Circular Dichroism Photoswitching with a Twist: Axially Chiral Hemiindigo. J. Am. Chem. Soc. 2018, 140 (42), 13558-13561.

(44) Huber, L. A.; Mayer, P.; Dube, H. Photoisomerization of Mono-Arylated Indigo and Water-Induced Aceleration of Thermal cis to trans Isomerization. ChemPhotoChem. 2018, 2, 458-464.

(45) Huang, C. Y.; Bonasera, A.; Hristov, L.; Garmshausen, Y.; Schmidt, B. M.; Jacquemin, D.; Hecht, S. N,N'-Disubstituted Indigos as Readily Available Red-Light Photoswitches with Tunable Thermal Half-Lives. J. Am. Chem. Soc. 2017, 139 (42), 15205-15211.

(46) Wiedbrauk, S.; Dube, H. Hemithioindigo-an emerging photoswitch. Tetrahedron Lett. 2015, 56 (29), 4266-4274.

(47) Lougheed, T.; Borisenko, V.; Hennig, T.; Rück-Braun, K.; Woolley, G. A. Photomodulation of ionic current through hemithioindigo-modified gramicidin channels. Org. Biomol. Chem. 2004, 2 (19), 2798-2801.
(48) Cordes, T.; Heinz, B.; Regner, N.; Hoppmann, C.; Schrader, T. E.; Summerer, W.; Rück-Braun, K.; Zinth, W. ChemPhysChem 2007, 8, 1713-1721.

(49) Kitzig, S.; Thilemann, M.; Cordes, T.; Rück-Braun, K. LightSwitchable Peptides with a Hemithioindigo Unit: Peptide Design, Photochromism, and Optical Spectroscopy. ChemPhysChem 2016, 17 (9), 1252-1263.

(50) Sailer, A.; Ermer, F.; Kraus, Y.; Lutter, F. H.; Donau, C.; Bremerich, M.; Ahlfeld, J.; Thorn-Seshold, O. Hemithioindigos for Cellular Photopharmacology: Desymmetrised Molecular Switch Scaffolds Enabling Design Control over the Isomer-Dependency of Potent Antimitotic Bioactivity. ChemBioChem 2019, 20 (10), 13051314.

(51) Dube, H.; Rebek, J., Jr. Selective guest exchange in encapsulation complexes using light of different wavelenghts. Angew. Chem., Int. Ed. 2012, 51 (13), 3207-3210.

(52) Guentner, M.; Uhl, E.; Mayer, P.; Dube, H. Photocontrol of Polar Aromatic Interactions by a Bis-Hemithioindigo Based Helical Receptor. Chem. - Eur. J. 2016, 22, 16433-16436.

(53) Wiedbrauk, S.; Bartelmann, T.; Thumser, S.; Mayer, P.; Dube, H. Simultaneous complementary photoswitching of hemithioindigo tweezers for dynamic guest relocalization. Nat. Commun. 2018, 9 (1), 1456.

(54) Tanaka, K.; Kohayakawa, K.; Iwata, S.; Irie, T. Application of 2-Pyridyl-Substituted Hemithioindigo as a Molecular Switch in Hydrogen-Bonded Porphyrins. J. Org. Chem. 2008, 73, 3768-3774.

(55) Huber, L. A.; Hoffmann, K.; Thumser, S.; Böcher, N.; Mayer, P.; Dube, H. Direct Observation of Hemithioindigo-Motor Unidirectionality. Angew. Chem., Int. Ed. 2017, 56, 14536-14539.

(56) Gerwien, A.; Mayer, P.; Dube, H. Photon-Only Molecular Motor with Reverse Temperature-Dependent Efficiency. J. Am. Chem. Soc. 2018, 140, 16442-16445.

(57) Uhl, E.; Thumser, S.; Mayer, P.; Dube, H. Transmission of Unidirectional Molecular Motor Rotation to a Remote Biaryl Axis. Angew. Chem., Int. Ed. 2018, 57, 11064-11068.

(58) Wilcken, R.; Schildhauer, M.; Rott, F.; Huber, L. A.; Guentner, M.; Thumser, S.; Hoffmann, K.; Oesterling, S.; de Vivie-Riedle, R.; Riedle, E.; Dube, H. Complete Mechanism of Hemithioindigo Motor Rotation. J. Am. Chem. Soc. 2018, 140, 5311-5318.

(59) Gerwien, A.; Mayer, P.; Dube, H. Green light powered molecular state motor enabling eight-shaped unidirectional rotation. Nat. Commun. 2019, 10 (1), 4449.

(60) Schildhauer, M.; Rott, F.; Thumser, S.; Mayer, P.; de VivieRiedle, R.; Dube, H. A Prospective Ultrafast Hemithioindigo Molecular Motor. ChemPhotoChem. 2019, 3, 365-371.

(61) Uhl, E.; Mayer, P.; Dube, H. Active and Unidirectional Acceleration of Biaryl Rotation by a Molecular Motor. Angew. Chem., Int. Ed. 2020, 59 (14), 5730-5737.

(62) Cordes, T.; Schadendorf, T.; Priewisch, B.; Rück-Braun, K.; Zinth, W. The Hammett Relationship and Reactions in the Excited Electronic State: Hemithioindigo Z/E-Photoisomerization. J. Phys. Chem. A 2008, 112, 581-588.

(63) Cordes, T.; Schadendorf, T.; Rück-Braun, K.; Zinth, W. Chemical control of Hemithioindigo-photoisomerization - Substituent-effects on different molecular parts. Chem. Phys. Lett. 2008, 455 (4-6), 197-201.

(64) Maerz, B.; Wiedbrauk, S.; Oesterling, S.; Samoylova, E.; Nenov, A.; Mayer, P.; de Vivie-Riedle, R.; Zinth, W.; Dube, H. Making fast photoswitches faster-using Hammett analysis to understand the limit of donor-acceptor approaches for faster hemithioindigo photoswitches. Chem. - Eur. J. 2014, 20 (43), 13984-13992.

(65) Wiedbrauk, S.; Maerz, B.; Samoylova, E.; Reiner, A.; Trommer, F.; Mayer, P.; Zinth, W.; Dube, H. Twisted Hemithioindigo Photoswitches: Solvent Polarity Determines the Type of LightInduced Rotations. J. Am. Chem. Soc. 2016, 138 (37), 12219-12227.

(66) Gerwien, A.; Schildhauer, M.; Thumser, S.; Mayer, P.; Dube, H. Direct evidence for hula twist and single-bond rotation photoproducts. Nat. Commun. 2018, 9 (1), 2510. 
(67) Wilcken, R.; Huber, L.; Grill, K.; Guentner, M.; Schildhauer, M.; Thumser, S.; Riedle, E.; Dube, H. Tuning the Ground and Excited State Dynamics of Hemithioindigo Molecular Motors by Changing Substituents. Chem. - Eur. J. 2020, 26 (59), 13507-13512.

(68) Dong, M.; Babalhavaeji, A.; Collins, C. V.; Jarrah, K.; Sadovski, O.; Dai, Q.; Woolley, G. A. Near-Infrared Photoswitching of Azobenzenes under Physiological Conditions. J. Am. Chem. Soc. 2017, 139 (38), 13483-13486.

(69) Dong, M.; Babalhavaeji, A.; Samanta, S.; Beharry, A. A.; Woolley, G. A. Red-Shifting Azobenzene Photoswitches for in Vivo Use. Acc. Chem. Res. 2015, 48 (10), 2662-2670.

(70) Lentes, P.; Stadler, E.; Rohricht, F.; Brahms, A.; Grobner, J.; Sonnichsen, F. D.; Gescheidt, G.; Herges, R. Nitrogen Bridged Diazocines: Photochromes Switching within the Near-Infrared Region with High Quantum Yields in Organic Solvents and in Water. J. Am. Chem. Soc. 2019, 141 (34), 13592-13600.

(71) Klaue, K.; Garmshausen, Y.; Hecht, S. Taking Photochromism beyond Visible: Direct One-Photon NIR Photoswitches Operating in the Biological Window. Angew. Chem., Int. Ed. 2018, 57 (5), 14141417.

(72) Moreno, J.; Gerecke, M.; Grubert, L.; Kovalenko, S. A.; Hecht, S. Sensitized Two-NIR-Photon Z->E Isomerization of a VisibleLight-Addressable Bistable Azobenzene Derivative. Angew. Chem., Int. Ed. 2016, 55 (4), 1544-1547.

(73) Baeyer, A.; Emmerling, A. Reduction des Isatins zu Indigblau. Ber. Dtsch. Chem. Ges. 1870, 3 (1), 514-517.

(74) Dealler, S. F.; Hawkey, P. M.; Millar, M. R. Enzymatic degradation of urinary indoxyl sulfate by Providencia stuartii and Klebsiella pneumoniae causes the purple urine bag syndrome. J. Clin. Microbiol. 1988, 26 (10), 2152-2156.

(75) Li, C.; Go, Y.; Mao, Z.; Koyano, K.; Kai, Y.; Kanehisa, N.; Zhu, Q.; Zhou, Z.; Wu, S. Bull. Chem. Soc. Jpn. 1996, 69, 1621-1627. (76) Schreiner, P. R.; Wittkopp, A. H-Bonding Additives Act Like Lewis Acid Catalysts. Org. Lett. 2002, 4, 217-220.

(77) Wyman, G. M. The interaction of excited thioindigo with hydroxylic compounds and its implications on the photostability of indigo. J. Chem. Soc. D 1971, No. 21, 1332-1334.

(78) Weinstein, J.; Wyman, G. M. Spectroscopic Studies on Dyes. II. The Structure of N,N'-Dimethylindigo1. J. Am. Chem. Soc. 1956, 78 (16), 4007-4010.

(79) Mallo, N.; Tron, A.; Andréasson, J.; Harper, J. B.; Jacob, L. S. D.; McClenaghan, N. D.; Jonusauskas, G.; Beves, J. E. HydrogenBonding Donor-Acceptor Stenhouse Adducts. ChemPhotoChem. 2020, 4 (6), 407-412.

(80) Zweig, J. E.; Newhouse, T. R. Isomer-Specific Hydrogen Bonding as a Design Principle for Bidirectionally Quantitative and Redshifted Hemithioindigo Photoswitches. J. Am. Chem. Soc. 2017, 139 (32), 10956-10959.

(81) Arai, T.; Ikegami, M. Novel Photochromic Dye Based on Hydrogen Bonding. Chem. Lett. 1999, 28, 965-966.

(82) Qian, H.; Pramanik, S.; Aprahamian, I. Photochromic Hydrazone Switches with Extremely Long Thermal Half-Lives. J. Am. Chem. Soc. 2017, 139 (27), 9140-9143.

(83) Helmy, S.; Read de Alaniz, J. Chapter Three - Photochromic and Thermochromic Heterocycles. Adv. Heterocycl. Chem. 2015, 117, 131-177.

(84) Ernst, O. P.; Lodowski, D. T.; Elstner, M.; Hegemann, P.; Brown, L. S.; Kandori, H. Microbial and Animal Rhodopsins: Structures, Functions, and Molecular Mechanisms. Chem. Rev. 2014, 114, 126-163.

(85) Nogly, P.; Weinert, T.; James, D.; Carbajo, S.; Ozerov, D.; Furrer, A.; Gashi, D.; Borin, V.; Skopintsev, P.; Jaeger, K.; Nass, K.; Bath, P.; Bosman, R.; Koglin, J.; Seaberg, M.; Lane, T.; Kekilli, D.; Brunle, S.; Tanaka, T.; Wu, W.; Milne, C.; White, T.; Barty, A.; Weierstall, U.; Panneels, V.; Nango, E.; Iwata, S.; Hunter, M.; Schapiro, I.; Schertler, G.; Neutze, R.; Standfuss, J. Retinal isomerization in bacteriorhodopsin captured by a femtosecond $\mathrm{x}$ ray laser. Science 2018, 361 (6398), eaat0094.
(86) Slavov, C.; Fischer, T.; Barnoy, A.; Shin, H.; Rao, A. G.; Wiebeler, C.; Zeng, X.; Sun, Y.; Xu, Q.; Gutt, A.; Zhao, K.-H.; Gärtner, W.; Yang, X.; Schapiro, I.; Wachtveitl, J. The interplay between chromophore and protein determines the extended excited state dynamics in a single-domain phytochrome. Proc. Natl. Acad. Sci. U. S. A. 2020, 117 (28), 16356-16362.

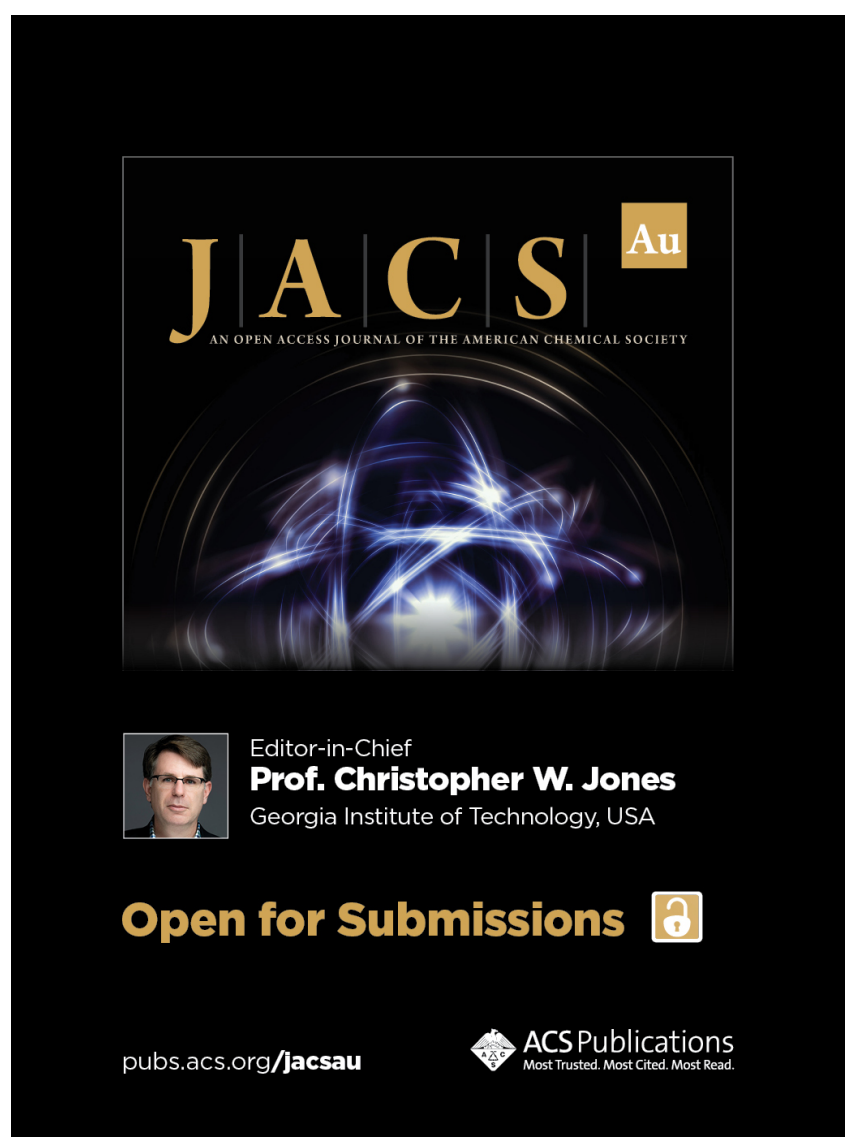

